\title{
Prospeç̧ão biotecnológica de bactérias endofíticas associadas à cactáceas
}

Os micro-organismos endofíticos são comumente representados por fungos ou bactérias, que colonizam diferentes tecidos em pelo menos uma parte de seu ciclo de vida com as plantas, sem desenvolver sintomas evidentes de doenças na planta hospedeira, caracterizando assim, relações simbióticas, mutuais ou até mesmo neutras. Os micro-organismos endofíticos constituem uma grande parte da diversidade microbiana ainda inexplorada, particularmente em plantas da família Cactaceae. A família Cactaceae é representada por plantas perenes, geralmente suculentas, sendo o Brasil, considerado o terceiro maior centro de diversidade das cactáceas no continente Americano. O conhecimento da comunidade endofítica associada a estas plantas é fundamental, pois, permite obter informações sobre a biodiversidade e bioprospecção microbiana, uma vez que a associação bacteriana endofítica deve refletir o seu grau de adaptação com espécies específicas de plantas hospedeiras, e também com o ambiente no qual está inserida, o que aprimora a produção de compostos bioativos em diversidade química e propriedades biológicas. Este estudo de revisão buscou analisar os relatos do isolamento de bactérias endofíticas associadas com espécies de cactáceas, devido estas possuírem grande importância na produção de biomoléculas ativas de interesse biotecnológico, o que possibilita a descoberta de novos bioprodutos que poderão ser bioprospectados na agricultura, indústria ou farmacologia.

Palavras-chave: Endófitos; Cactáceas; Biomoléculas; Bioprospecção.

\section{Biotechnological prospection of endophytic bacteria associated with cactaceae}

Endophytic microorganisms are commonly represented by fungi or bacteria that colonize different tissues in, at least, one part of their life cycle with plants, without developing evident symptoms of diseases in the host plant, thus, characterizing symbiotic relations that can be mutual or even neutral. Endophytic microorganisms represent a great part of a microbial diversity still unexplored, particularly in plants of the Cactaceae family. The Cactaceae family is constituted by perennial plants, usually succulent plants, and Brazil is considered the third biggest center when it comes to diversity of Cactaceae in the American continent. Knowledge on the endophytic community associated with these plants is essential, for it allows obtaining information on biodiversity and microbial bioprospecting, since endophytic bacterial association must reflect its degree of adaptation to host plants, and also to its environment, which refines the production of bioactive compounds in chemical diversity and biological properties. This review study sought to analyze reports on the isolation of endophytic bacteria associated with species of Cactaceae, since the latter are of great importance for the production of active biomolecules of biotechnological interest, which allows finding new bioproducts that can be bioprospected in agriculture, industry or pharmacology.

Keywords: Endophytes; Cacti; Biomolecules; Bioprospection.

Topic: Uso de Recursos Naturais

Reviewed anonymously in the process of blind peer.
Received: 03/02/2021

Approved: $26 / 02 / 2021$
Jesieli Beraldo-Borrazzo (iD

Universidade Estadual de Maringá, Brasil http://lattes.cnpq.br/5022659591209605 http://orcid.org/0000-0002-7628-3057 jesieliberaldo@gmail.com

\section{Claudete Aparecida Mangolin (iD}

Universidade Estadual de Maringá, Brasil http://lattes.cnpq.br/6483114881983756 http://orcid.org/0000-0002-1653-3106 mangolimca@gmail.com

Maria de Fatima Pires da Silva Machado Universidade Estadual de Maringá, Brasil http://lattes.cnpq.br/4904738150188587 http://orcid.org/0000-0001-7815-4606 mfpsmachado@uem.br

DOI: 10.6008/CBPC2179-6858.2021.002.0049
Referencing this:

BERALDO-BORRAZZO, J.; MANGOLIN, C. A.; MACHADO, M. F. P. S. Prospecção biotecnológica de bactérias endofíticas associadas à cactáceas. Revista Ibero Americana de Ciências Ambientais, v.12, n.2, p.567-579, 2021. DOI: http://doi.org/10.6008/CBPC2179$\underline{6858.2021 .002 .0049}$ 


\section{INTRODUÇÃO}

Plantas e micro-organismos são capazes de estabelecer uma relação mutualística entre si, em que as plantas como um organismo simbionte, desenvolveram estratégias destinadas a selecionar comunidades microbianas úteis, cujas características garantem funções favoráveis para a planta. A interação dos microorganismos com sua planta hospedeira dá origem ao chamado fitomicrobioma (UROZ et al., 2019). De acordo com Bettenfeld et al. (2019), plantas e os micro-organismos associados não podem ser considerados como organismos independentes, mas sim como uma única unidade evolutiva, denominada de holobiont, resultante de uma ampla interação de micro-organismos epifíticos e endofíticos por todos os compartimentos da planta, como endosfera, filosfera e rizosfera. Além disso, há a ocorrência de um processo de cascata microbiana envolvendo todos os reinos do ecossistema, que amplia o conceito de holobiont para eco-holobiont ou superorganismo, uma vez que que há o condicionamento direto ou indireto de microorganismos associados à planta hospedeira, através de múltiplos meios de interação, como do tipo biótica e abiótica em todos os níveis multitróficos da planta (SINGH et al., 2020). Como resultado destas interações há uma alta diversidade na composição taxonômica de micro-organismos associados às plantas, que estabelece o chamado núcleo funcional microbiano. O núcleo funcional microbiano desempenha um conjunto de funções essenciais tanto para a planta hospedeira quanto para a comunidade microbiana, tais como: nutrição, desenvolvimento da planta por biomoléculas microbianas, além de desempenhar serviços ecossistêmicos importantes como especiação vegetal e impacto sobre ciclos geoquímicos (LEMANCEAU et al., 2017).

A diversidade de plantas existentes nos biomas brasileiros (Caatinga, Cerrado, Mata Atlântica, Pampas, Pantanal e Amazônia) representa uma fonte importante de endófitos, em virtude destes habitats serem considerados únicos por abrigar abundância de espécies com endemismo e raridade global (APGAUA et al., 2014; REZENDE et al., 2018; ROCHA et al., 2015; STRASSBURG et al., 2017). Diversos micro-organismos endofíticos são encontrados em associação específica com plantas típicas destes locais, muitas com propriedades medicinais (ORLANDELLI et al., 2012; PÁDUA et al., 2019).

Deste modo, o conhecimento de micro-organismos associados às plantas é fundamental por promover a descoberta de novas espéceis microbianas com potencial biotecnológico, como para produção de enzimas de interesse industrial (LEE et al., 2014; ORLANDELLI et al., 2015), produção de compostos de interesse farmacêutico (BUNGIHAN et al., 2011; FLORES et al., 2013; SPECIAN et al., 2012) e para o controle biológico de patógenos (PAMPHILE et al., 2004), entre outras aplicações. O conhecimento de microorganismos associados às plantas também é fundamental para forncer informações ecológicas importantes, através da identificação da diversidade e distribuição global microbiana.

\section{METODOLOGIA}

A revisão da literatura foi realizada a partir da análise sistemática dos estudos publicados sobre o tema, e seguiu especificações conforme Gough et al. (2012), Moher et al. (2015) e Sampaio et al. (2007) 
(Figura 1).

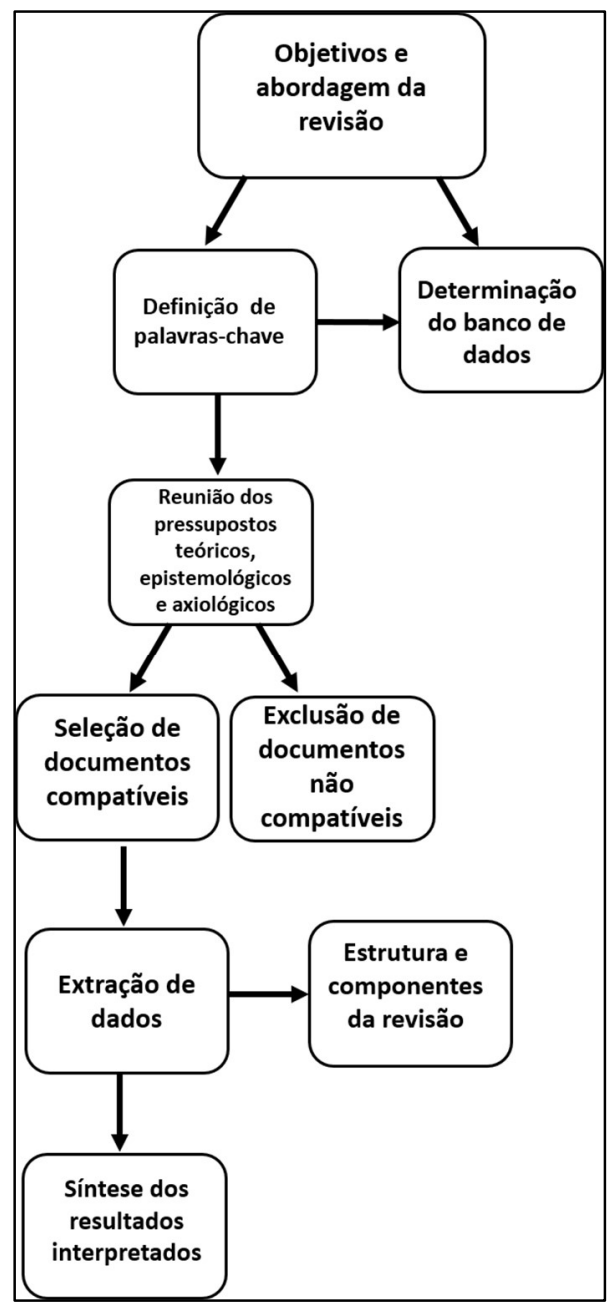

Figura 1: Mapa conceitual para elaboração de revisão bibliográfica da literatura.

A busca de documentos foi realizada sem delimitação de ano de publicação, nas bases de dados online como Google Scholar ${ }^{1}$, SCOPUS ${ }^{2}$, Science Direct ${ }^{3}$ e SciFinder ${ }^{4}$, utilizando as palavras-chave ou combinação de termos: 'endophytic microorganisms', 'Cactaceae', 'endophytic bacteria', 'bioprospecting'. Quantitativamente a pesquisa resultou em cerca de dez mil trabalhos, e após a seleção por documentos compatíveis ao tema, foram selecionados 82 trabalhos para a elaboração da síntese dos resultados interpretados.

\section{DISCUSSÃO TEÓRICA}

\section{Importância dos Micro-organismos Endofíticos}

A endofitologia foi definida por Unterseher et al. (2012), como o estudo de micro-organismos denominados endofíticos. $O$ início das pesquisas com endófitos remonta ao ano de 1866, quando o botânico alemão Anton de Bary introduziu pela primeira vez o termo "endófitos", para qualquer microrganismo

${ }^{1}$ https://scholar.google.com.br/

2 https://www.scopus.com/

${ }^{3}$ https://www.sciencedirect.com/

4 https://sso.cas.org/ 
existente no interior das plantas (SINGH et al., 2017). Os micro-organismos endofíticos são atualmente representados por fungos e bactérias que colonizam o interior de tecidos vegetais saudáveis, em alguma parte de seu ciclo de vida sem causar danos aparentes à planta hospedeira (AZEVEDO et al., 2000).

Os endófitos que se estabelecem no interior das plantas se originam a partir da existência de um microbioma ambiental, provenientes da rizosfera ou filosfera. O meio de entrada mais comum utilizado pelos endófitos é através do solo, por aberturas naturais ou feridas localizadas nas raízes. Também, é possível a entrada por meio dos estômatos ou hidatódios e por aberturas causadas por insetos ou mesmo fungos fitopatogênicos por meio de seus apressórios. Além disso, a transferência dos endófitos ocorre entre a planta materna aos seus descendentes, por transmissão vertical via sementes ou através da propagação vegetativa (AZEVEDO, 1998). Dessa maneira, os endófitos apresentam a capacidade de se disseminar sistematicamente pelo hospedeiro vegetal, habitando desde vasos condutores a apoplasto, havendo eventualmente colonização intracelular (LACAVA et al., 2018).

O estudo da associação da microbiota endofítica com seu hospedeiro vegetal, inicia-se com o isolamento de tecidos previamente desinfetados superficialmente, para a eliminação de micro-organismos epifíticos (SOBRAL et al., 2014). Os endófitos podem ser isolados de diferentes tecidos e órgãos vegetais, incluindo raízes, caules, folhas, sementes, pólen, anteras e estames. As raízes e folhas são as amostras mais comumente utilizadas, porque os endófitos encontrados na maioria das plantas são transmitidos horizontalmente, ou seja, quando a transmissão ocorre entre as plantas e o meio ambiente, assim as raízes e as folhas mais velhas, tendem a ter maior número de endófitos (ARNOLD, 2008). Deve-se considerar acerca do isolamento da comunidade endofítica de uma amostral vegetal de interesse, que ocorre naturalmente a predominância de determinados gêneros (espécies dominantes), e baixa frequência de outros gêneros (espécies secundárias) (PAMPHILE et al., 2002). Há também uma estrita relação entre a presença de espécies de micro-organismos endofíticos específicas a órgãos ou tecidos da planta, pois, segundo Fernandes et al. (2015), Manjunatha et al. (2019) e Robinson et al. (2016), a ocorrência de determinadas espécies difere conforme o tecido e/ou órgão vegetal alvo do isolamento em plantas de soja, trigo e milheto, respectivamente.

Após o isolamento dos endófitos, a posterior caracterização pode ser realizada por observações morfológicas e comparação das mesmas com as estruturas descritas na literatura (ARAÚJO et al., 2010). Além das observações morfológicas, as técnicas moleculares têm sido projetadas para a caracterização dos endófitos porque possibilitaram avanços no processo de identificação, devido à grande sensibilidade e especificidade para a diferenciação genética (MAGNANI et al., 2005).

A bioprospecção de micro-organismos endofíticos tem sido considerada um recurso promissor na busca por novas biomoléculas para diversas aplicações biotecnológicas (ORLANDELLI et al., 2015). A descoberta de novos compostos bioativos produzidos por meio dos micro-organismos endofíticos, desencadeou uma nova era para biotecnologia endofítica, em razão destas substâncias comporem uma classe natural de moléculas, levando a uma maior qualidade das formulações geradas e minimizando assim, 
impactos dos processos ao meio ambiente (COSTA et al., 2018). De acordo com a base de dados SCOPUS utilizando 'micro-organismos endofíticos' como palavra-chave e limitando-se a artigos como tipo de documento, entre os anos de 2000 e 2020 foram publicados 2.697 trabalhos, dentre estes, aproximadamente 28.8\% foram desenvolvidos nas áreas de Ciências Agrárias e Biológicas, seguidos por Imunologia e Microbiologia (20.0\%) e Bioquímica, Genética e Biologia Molecular (19.0\%) (Figura 2).

Pressupõe-se que muitas propriedades químicas detectadas nos extratos obtidos das plantas, os quais atribuem caráter medicinal as mesmas, são conferidas pela síntese de metabólitos dos endófitos (AZEVEDO et al., 2002). Assim, tem sido considerado que uma das vias de produção de moléculas bioativas em vegetais, é estabelecida por meio da relação simbiótica entre a comunidade endofítica e a planta, sendo que a interação estável entre endófitos e suas plantas hospedeiras é dependente da resposta metabólica de ambos (EATON et al., 2011; PIZA et al., 2015).

Portanto, os micro-organismos endofíticos possuem reconhecida importância por estarem relacionados à produção de biomoléculas atuantes na planta, como por exemplo, na proteção contra herbívoria (KOGEL et al., 2006), estresse hidríco (KAVAMURA et al., 2013), na promoção de crescimento vegetal (GLICK, 2014) e na proteção contra fitopatógenos (SERRANO et al., 2012). Adicionalmente, os compostos bioativos produzido pelos micro-organismos endofíticos também apresentam outras atividades biológicas comprovadas, tais como atividades antitumoral (JEEWON et al., 2019), antioxidante (CHATTERJEE et al., 2019), antiparasitária (ALMEIDA et al., 2018) e imunomoduladora (THATOI et al., 2013).

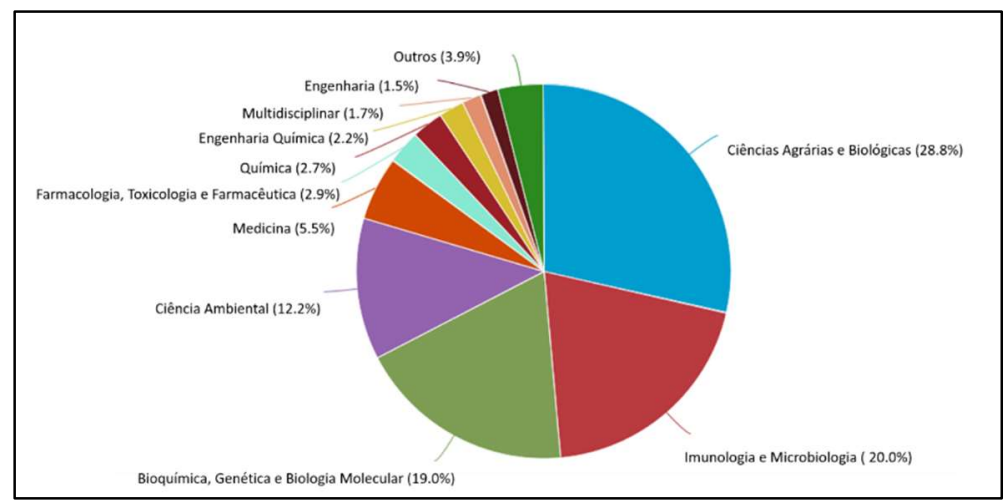

Figura 2: Áreas de maior emprego de micro-organismos endofíticos, de acordo com a base de dados SCOPUS: utilizando "micro-organismos endofíticos" como palavra-chave entre os anos de 2000 e 2020 . Acessado em agosto de 2020.

\section{Cactáceas como Espécie Hospedeira de Bactérias Endofíticas}

Plantas da família Cactaceae distribuem-se desde o Norte do Canadá até a Patagônia na Argentina, mas há relatos da ocorrência da espécie em pelos menos outros três continentes como: Ásia, África e Europa (MEIADO et al., 2015; WALLACE et al., 2002). Este grupo de plantas possui 130 gêneros composto por aproximadamente 2.000 espécies. O maior centro de diversidade das cactáceas encontra-se no México, contudo, outros países como Brasil, Costa Rica, Bolívia, Chile e Peru, possuem um número importante de espécies de cactos (SANTOS-DÍAZ et al., 2019). A família Cactaceae encontra-se dividida em quatro

\footnotetext{
${ }^{5}$ https://www.scopus.com/
} 
subfamílias: Maihuenioideae, Pereskioideae, Opuntioideae e Cactoideae (ANDERSON, 2001; BARTHLOTT et al., 1993).

A maior parte das éspecies de cactos são endêmicas de florestas tropicais secas, devido a capacidade de se desenvolverem principalmente em regiões áridas e semi-áridas (ANDERSON, 2001). É considerado uma característica marcante deste grupo de plantas, seus caules suculentos e espinhosos que apresentam uma grande variedade de formas, como do tipo colunar, globoso, oval, cilíndrico, e dentre outros (BRITTON et al., 1963). As florestas tropicais secas compõe cerca de metade das florestas tropicais existentes no mundo, as quais, são representadas por grandes áreas localizadas na América Central e do Sul, África, Sudeste Asiático, Austrália e Índia (CECCON et al., 2006; MURPHY et al., 1986). Estes ecossistemas representam nichos ecológicos únicos do ponto de vista evolutivo, pois selecionam organismos capazes de prosperar em condições bióticas e abióticas adversas. Porém, de acordo com a literatura apenas $14 \%$ das pesquisas realizadas para o conehcimento da biodiversidade, ocorrem em localidades onde há presença de florestas tropicais secas, concentrando-se o restante das pesquisas em florestas tropicais de regiões úmidas (BEZERRA et al., 2013; SÁNCHES-AZOFEIFA et al., 2005).

O Brasil apresenta um total de 37 gêneros de cactáceas nativas, o que corresponde a cerca de $30 \%$ das espécies relatadas nas Américas (ZAPPI et al., 2010). Por essa razão, é considerado o terceiro maior centro de diversidade das cactáceas no continente Americano (OLDFIELD, 1997). A floresta tropical seca encontrada no Brasil é chamada de Caatinga. Localizada no Nordeste brasileiro, este bioma possui a maior diversidade das espécies de cactos do país (ZAPPI et al., 2015). Apesar da Caatinga concentrar o maior número de espécies de cactáceas, também há representantes em outros domínios fitogeográficos do país como no Cerrado, Mata Atlântica, Pampas, Pantanal e Amazônia (VELOSO et al., 1991).

Os cactos são peculiares devido ao seu extenso conjunto de adaptações especiais, que lhes permite serem espécies perenes sob condições extremas de estresse ambiental (ROJAS-ARÉCHIGA et al., 2000). O desenvolvimento de estruturas anatômicas e morfológicas modificadas propiciou as cactáceas, uma alta eficiência do uso de água permitindo sua sobrevivência em ambientes extremos com escassez de água ou com altas temperaturas, como por exemplo, possuem epiderme espessa coberta por uma cutícula cerosa (impermeável), folhas modificadas em formas de espinhos (aréolas) e uma hipoderme suculenta (tecido aquoso) com células mucilaginosas (TERRAZAS et al., 2002). Os cactos exibem características metabólicas como o metabolismo ácido crassuláceo (CAM), e por isso, são chamadas também de plantas CAM. Por serem capazes de realizarem as reações fotossintéticas independente da luz, as cactáceas reduzem substancialmente a quantidade da perca de água, mantendo seus estômatos fechados durante o dia, e durante a noite, quando a taxa de vapor de agua é reduzida, abrem seus estômatos e fixam $\mathrm{CO}_{2}(\mathrm{ORTEGA}$ BAES et al., 2010).

O conhecimento sobre a ocorrência de bactérias endofíticas em cactos quanto a sua identidade e diversidade é um importante estudo a ser desenvolvido, isto porque os cactos, são considerados plantas vasculares com modificações únicas. A presença de fatores ambientais extremos favorece a seleção de organismos capazes de suportar as contrastantes condições impostas pelo clima, e a associação da 
comunidade bacteriana endofítica, deve refletir o seu grau de adaptação com planta hospedeira e especificamente com o ambiente no qual está inserida (BORDENSTEIN et al., 2015; NAMWONGSA et al., 2019; UNTERSEHER et al., 2016). Como os micro-organismos endofíticos constituem uma grande parte da diversidade microbiana ainda inexplorada (AKINSANYA et al., 2015; BEZERRA et al., 2013; BULGARELLI et al., 2013), a oportunidade de encontrar novas éspecies microbianas associadas a este grupo de plantas com potencial biotecnológico é promissora.

A Tabela 1 aponta os estudos que exploraram o isolamento de bactérias endofíticas associadas a cactos distribuídos por diversas regiões do globo terrestre. Vinte e três gêneros diferentes de bactérias endofíticas foram identificados nos estudos com somente 10 espécies de sete gêneros de cactos (Cereus, Euphorbia, Mammillaria, Melocactus, Myrtillocactus, Opuntia e Pachycereus). Espécies de cactos do gênero Opuntia foram as mais estudadas (Opuntia ficus-indica, Opuntia nopalea, Opuntia robusta e Opuntia spp.). 0 gênero Bacillus foi identificado no maior número de espécies de cactos (Pachycereus pringlei, Mammillaria fraileana, Opuntia ficus-indica, Cereus jamacaru, Melocactus sp., Pilosocereus gounellei, Opuntia nopalea, Euphorbia trigonas Mill). O gênero Enterobacter foi identificado em seis espécies (Mammillaria fraileana, Opuntia ficus-indica, Cereus jamacaru, Melocactus sp., Pilosocereus gounellei, Euphorbia trigonas Mill), e os gêneros Pseudomonas e Pantoea foram identificados em cinco espécies de cactos, respectivamente [Pseudomonas: Pachycereus pringlei, Mammillaria fraileana, Cereus jamacaru, Melocactus zehntneri, Euphorbia trigonas) e Pantoea (Opuntia ficus-indica, Cereus jamacaru, Melocactus sp., Pilosocereus gounellei, Melocactus zehntneri)]. Os demais gêneros de bactérias listados na Tabela 1 (Azospirillum, Paenibacillus, Arthrobacter, Gordonia, Cellulosimicrobium, Nocardia, Azatobacter, Stenotrophomonas, Rhizobium, Burkholderia, Klesbsiella, Staphylococcus, Acinetobacter, Ochrobactrum, Herbaspirillum, Azomonas, Methylobacterium, Lysinibacillus, e Lelliottia) foram identificados em três, duas, ou somente uma espécie de cacto.

Tabela 1: Relação de estudos sobre a diversidade de bactérias endofíticas associadas às espécies de Cactaceae.

\begin{tabular}{|c|c|c|c|c|c|c|}
\hline Espécie de cacto & Bactéria endofítica & $\begin{array}{l}\text { Tecido de } \\
\text { isolamento }\end{array}$ & $\begin{array}{l}\text { Biomoléculas } \\
\text { isoladas }\end{array}$ & $\begin{array}{l}\text { Método de } \\
\text { identificação }\end{array}$ & Localidade & Referência \\
\hline $\begin{array}{l}\text { Pachycereus } \\
\text { pringlei }\end{array}$ & $\begin{array}{l}\text { Bacillus spp. } \\
\text { Klesbsiella spp. } \\
\text { Staphylococcus spp. } \\
\text { Pseudomonas spp. } \\
\text { Pseudomonas sp. }\end{array}$ & Raiz & $\begin{array}{l}\text { Ácidos } \\
\text { orgânicos }\end{array}$ & Gene 16S rRNA & México & $\begin{array}{l}\text { Puente et al. } \\
\text { (2009) }\end{array}$ \\
\hline $\begin{array}{l}\text { Mammillaria } \\
\text { fraileana }\end{array}$ & $\begin{array}{l}\text { Enterobacter sp. } \\
\text { Bacillus sp. } \\
\text { Azatobacter sp. } \\
\text { Azospirillum sp. } \\
\text { Pantoea sp. }\end{array}$ & $\begin{array}{l}\text { Raiz } \\
\text { Caule } \\
\text { Sementes }\end{array}$ & - & Gene 16S rRNA & México & $\begin{array}{l}\text { Lopez et al. } \\
\text { (2011) }\end{array}$ \\
\hline $\begin{array}{l}\text { Opuntia ficus- } \\
\text { indica }\end{array}$ & $\begin{array}{l}\text { Stenotrophomonas sp. } \\
\text { Acinetobacter sp. } \\
\text { Ochrobactrum sp. } \\
\text { Enterobacter sp. } \\
\text { Bacillus sp. }\end{array}$ & $\begin{array}{l}\text { Raiz } \\
\text { Caule }\end{array}$ & AIA & Bioquímico & Brasil & $\begin{array}{l}\text { Costa e Melo } \\
\text { (2012) }\end{array}$ \\
\hline $\begin{array}{l}\text { Cereus jamacaru } \\
\text { Melocactus sp. } \\
\text { Pilosocereus } \\
\text { gounellei }\end{array}$ & $\begin{array}{l}\text { Bacillus sp. } \\
\text { Paenibacillus sp. } \\
\text { Enterobacter sp. } \\
\text { Pantoea sp. } \\
\text { Arthrobacter sp. } \\
\text { Gordonia sp. }\end{array}$ & Rizosfera & $\begin{array}{l}\text { EPS } \\
\mathrm{AIA} \\
\mathrm{NH}_{3}\end{array}$ & $\begin{array}{l}\text { Gene } 16 \mathrm{~S} \text { rRNA } \\
\text { Bioquímico }\end{array}$ & Brasil & $\begin{array}{l}\text { Kavamura et } \\
\text { al. (2013) }\end{array}$ \\
\hline
\end{tabular}




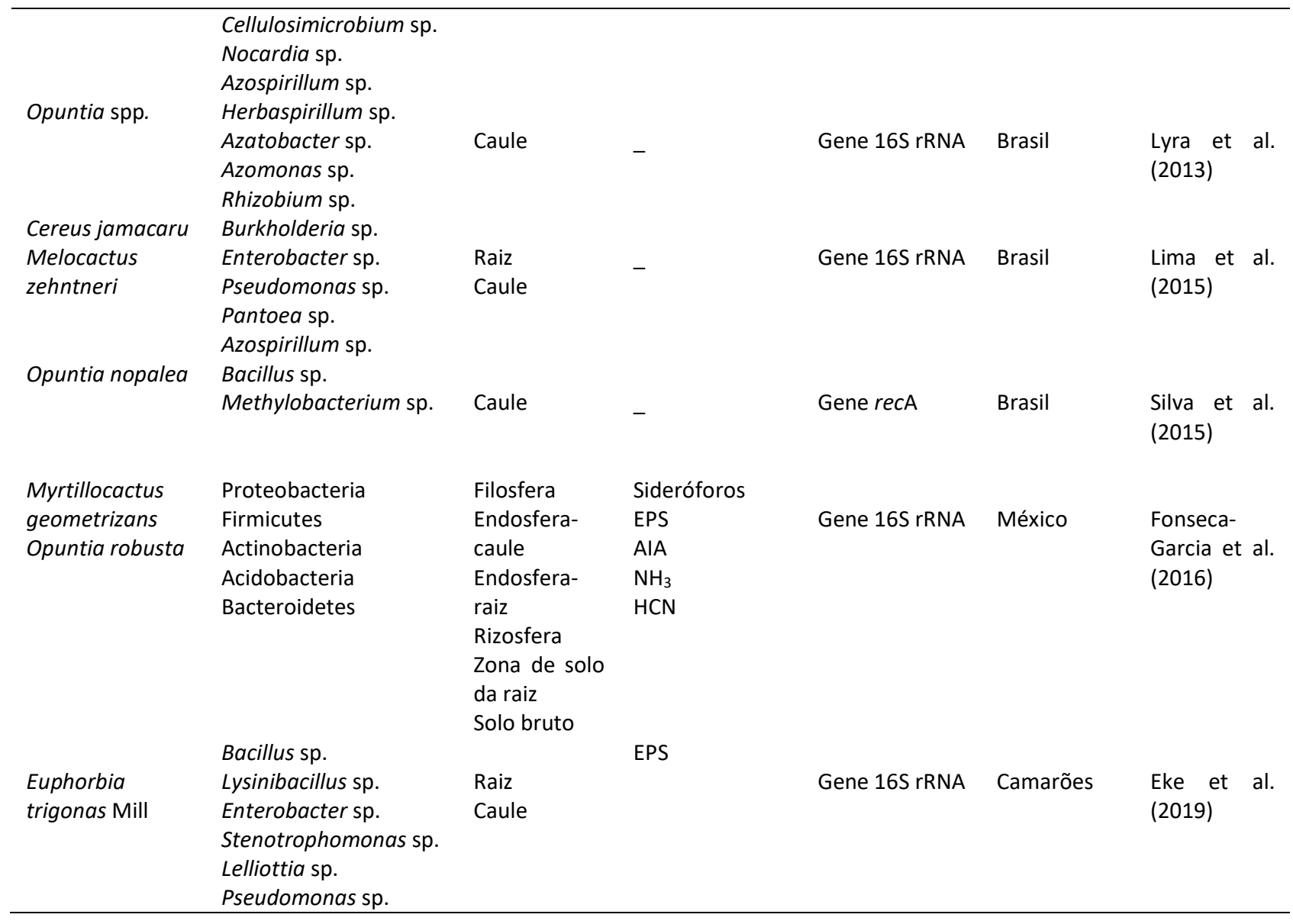

Estima-se que a identificação de biomoléculas produzidas pelas bactérias endofíticas isoladas de diferentes espécies de cactos, correspodam a apenas $55 \%$ das pesquisas (Tabela 1 ). Através de interações biológicas específicas com sua planta hospedeira, as bactérias endofíticas tornaram-se evolutivamente fontes otimizadas para a produção de compostos bioativos de grande diversidade química e com propriedades validadas por vias biológicas (LI et al., 2018). De acordo com a Figura 3, as biomoléculas isoladas com maiores frequências entre diferentes espécies de bactérias endofíticas em associação com espécies de cactos, foram o ácido 3-indol-acético (AIA) e os exopolissacarídeos (EPS).

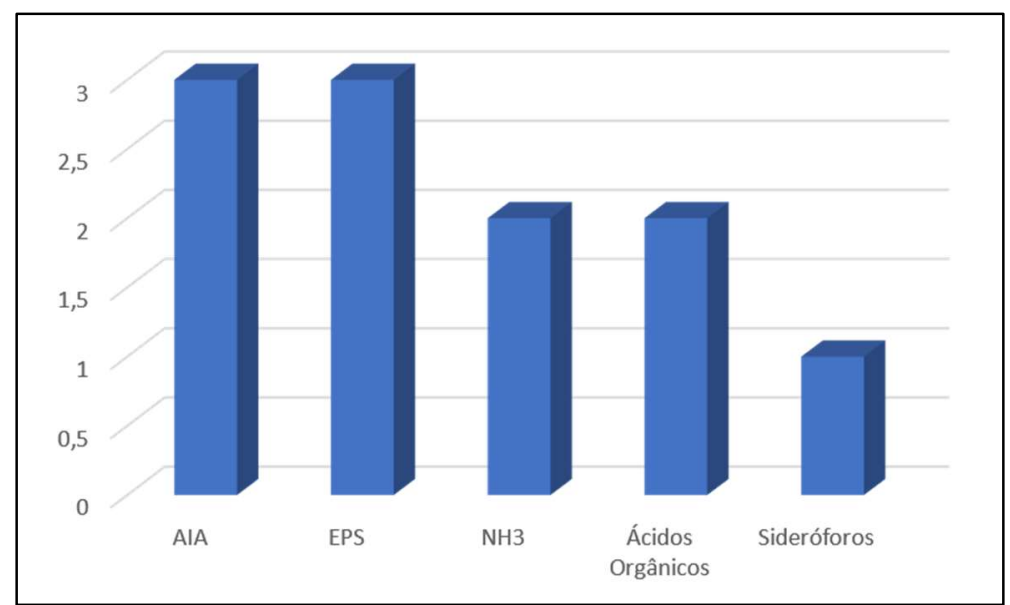

Figura 3: Diversidade de biomoléculas produzidas por bactérias endofíticas isoladas de cactos. AIA= Ácido 3-indolacético; EPS= Exopolissacarídeos; $\mathrm{NH}_{3}=$ Amônia.

As bactérias endofíticas são capazes de regular e produzir quantidades fisiologicamente ativas de 
auxina, um fitohormônio que atua diretamente no controle da proliferação celular vegetal, diferenciação dos tecidos e alongamento celular dependente de luz (SHOKRI et al., 2010), contribuindo para a promoção do desenvolvimento vegetal (GLICK, 2014). De acordo com Etesami et al. (2015), o AIA bacteriano é capaz de aumentar e modificar o sistema radicular vegetal, por meio de processos regulatórios, proporcionando a planta maior acesso a nutrientes do solo e absorção de água. Do ponto de vista biotecnológico, o uso de bactérias endofíticas produtoras de auxina como biofertilizantes, pode contribuir para o aumento da produtividade em culturas agrícolas importantes.

Os exopolissacarídeos microbianos, são biopolímeros de carbiodratos produzidos pelas bactérias endofíticas, como proteção em resposta a fotores de estresse ambientais (LIU et al., 2017). Por serem considerados um polímero de origem natural, o que confere características como biocompatibilidade e biodegradável, a biossíntese de EPS bacterianos possui diversas aplicabilidades biotecnológicas (ABD-ALLA et al., 2018). Os EPS possuem grande importância na indústria alimentícia, onde são utilizados como espessantes a exemplo da goma dextrana, xantana, alginato, curdulana e gelana (MISHRA et al., 2013), além de apresentam atividades biológicas diversas, como imunomoduladora e antitumoral, impactando na formulação de produtos farmacêuticos e na terapia médica (LIU et al., 2010; YOUSEF et al., 2020).

\section{CONCLUSÕES}

As bactérias endofíticas constituem-se um recurso genético valioso para o desenvolvimento de bioprodutos de importância biotecnológica, uma vez que a associação de plantas com micro-organismos endofíticos possui alto potencial como fonte para obtenção de produtos naturais, em comparação com as plantas isoladamente. A diversidade bacteriana endofítica e das moléculas por elas sintetizadas está diretamente relacionada a associações complexas e específicas com espécies de plantas hospedeiras, como resultado de um processo de co-evolução entre planta-endófitos. A capacidade Biosintética para a produção de moléculas biologicamente relevantes é atribuída a relação simbiótica estabelecida entre estes organismos, desenvolvida para executar diversas funções biológicas requeridas desta relação.

Contudo, este potencial é praticamente inexplorado quando se refere a associação de bactérias endofíticas ao grupo de plantas da família Cacatacea. Somente 10 espécies de sete gêneros de cactos (Cereus, Euphorbia, Mammillaria, Melocactus, Myrtillocactus, Opuntia e Pachycereus) foram estudadas até o presente, com o objetivo de identificar bactérias endofíticas associadas a estas espécies de cactos. 0 potencial desta família de plantas (Cactaceae) como fonte de diversidade bacteriana endofítica, e das moléculas por elas sintetizadas, parece promissor uma vez que nas 10 espécies investigadas foram identificados 23 gêneros diferentes de bactérias. O gênero Bacillus foi identificado no maior número de espécies de cactos (em oito espécies), o gênero Enterobacter foi identificado em seis espécies, e os gêneros Pseudomonas e Pantoea foram identificados em cinco espécies de cactos. Os outros demais gêneros de bactérias (19) foram identificados em três, duas, ou somente uma espécie de cacto. A perspectiva é que a partir do conhecimento da diversidade de micro-organismos endofíticos associados com as cactáceas, será possível alcançar novas descobertas em processos biológicos relacionados à taxonomia, ecologia e 
biotecnologia de produtos naturais produzidos pela comunidade endofítica estabelecida nestas plantas, os quais, poderão ser prospectados em diferentes áreas, desde a agrícola, médica, farmacêutica, ambiental e alimentícia.

\section{REFERÊNCIAS}

ABD-ALLA, M. H.; BASHANDY, S. R.; NAFADY, N. A.; HASSAN, A. A.. Enhancement of exopolysaccharide production by Stenotrophomonas maltophilia and Brevibacillus parabrevis isolated from root nodules of Cicer arietinum L. and Vigna unguiculata L. (Walp.) plants. Rendiconti Lincei. Scienze Fisiche e Naturali, v.29, p.117-129, 2018. DOI: https://doi.org/10.1007/s12210-018-0671-1

AKINSANYA, M. A.; GOH, J. K.; LIM, S. P.; TING, A. S. Y.. Metagenomics study of endophytic bacteria in Aloe vera using next-generation technology. Genomics Data, v.6, p.159-163, 2015. DOI:

https://doi.org/10.1016/i.gdata.2015.09.004

ALMEIDA, T. T.; RIBEIRO, M. A. S.; POLONIO, J. C.; GARCIA, F. P.; NAKAMURA, C. V.; MEURER, E. C.; SARRAGIOTTO, M. H.; BALDOQUI, D. C.; AZEVEDO, J. L.; PAMPHILE, J. A.. Curvulin and spirostaphylotrichins $R$ and $U$ from extracts produced by two endophytic Bipolaris sp. associated to aquatic macrophytes with antileishmanial activity. Natural Product Research, v.32, n.23, p.783-2790, 2018. DOI: https://doi.org/10.1080/14786419.2017.1380011

ANDERSON, E. F.. The cactus family. Portland: Timber Press, 2001.

APGAUA, D. M. G.; SANTOS, R. M.; PEREIRA, D. G. S.; MENINO, G. C. O.; PIRES, G. G.; FONTES, M. A. L.; TNG, D. Y. $P$.. Beta-diversity in seasonally dry tropical forests (SDTF) in the Caatinga biogeographic domain, Brazil, and its implications for conservation. Biodiversity and Conservation, v.23, p.217-232, 2014. DOI: https://doi.org/10.1007/s10531-013-0599-9

ARAÚJO, W. L.; LACAVA, P. T.; MARCO, J.; LIMA, A. O.; SOBRAL, J. K.; AZEVEDO, J. L.; PIZZIRANI-KLEINER, A. A.. Guia prático: isolamento e caracterização de micro-organismos endofíticos. Piracicaba: ESALQ, 2010.

ARNOLD, A. E.. Hidden within our botanical richness, a treasure trove of fungal endophytes. The Plant Press, v.32, p.13-15, 2008.

AZEVEDO, J. L.. Micro-organismos endofíticos. In: MELO, I. S.; AZEVEDO, J. L.. Ecologia Microbiana. Jaguariúna: EMBRAPACNPMA, 1998. p.117-137.

AZEVEDO, J. L.; MACCHERONI JUNIOR, J.; PEREIRA, O.; ARAÚJO, W. L.. Endophytic microorganisms: a review on insect control and recent advances on tropical plants. Electronic Journal of Biotechnology, v.3, n.1, p.40-65, 2000.

AZEVEDO, J. L.; MACCHEORI, W. J.; ARAÚJO, W. L.; PEREIRA, J. O.. Micro-organismos endofíticos e seu papel em plantas tropicais. In: SERAFINI, L. A.; BARROS, N. M., AZEVEDO, J. L.. Biotecnologia: avanços na agricultura e na agroindústria. Caxias do Sul: EDUCS, 2002. p.233-268.
BARTHLOTT, W.; HUNT, D. R.. Cactaceae. In: KUBITZKI, K. The families and genera of vascular plants. Berlin: SpringerVerlag, 1993. p.161-197.

BETTENFELD, P.; FONTAINE, F.; TROUVELOT, S.; FERNANDEZ, O.; COURTY, P. E.. Woody plant declines. What's wrong with the microbiome?. Trends in Plant Science, v.25, n.4, p.381394, 2019. DOI: https://doi.org/10.1016/j.tplants.2019.12.024

BEZERRA, J. D. P.; SANTOS, M. G. S.; BARBOSA, R. N.; SVEDESE, V. M.; LIMA, D. M. M.; FERNANDES, M. J. S.; GOMES, B. S.; PAIVA, L. M.; ALMEIDA-CORTEZ, J. S.; SOUZAMOTTA, C. M.. Fungal endophytes from cactus Cereus jamacaru in Brazilian tropical dry forest: a first study. Symbiosis, v.60, p.53-63, 2013. DOI: https://doi.org/10.1007/s13199-013-0243-1

BORDENSTEIN, S. R.; THEIS, K. R.. Host biology in light of the microbiome: ten principles of holobionts and hologenomes. Plos One, v.13, n.8, p.e1002226, 2015. DOI: https://doi.org/10.1371/journal.pbio.1002226

BRITTON, N. L.; ROSE, J. N.. The Cactaceae: description and illustrations of plants of the cactus family. New York: Dover, 1963.

BULGARELLI, D.; SCHLAEPPI, K.; SPAEPEN, S.; VAN THEMAAT, E. V. L.; SCHULZE-LEFERT, P.. Structure and functions of the bacterial microbiota of plants. Annual Review of Plant Biology, v.64, p.807-838, 2013. DOI: https://doi.org/10.1146/annurev-arplant-050312-120106

BUNGIHAN, M. E.; TAN, M. A.; KATAJIMA, M.; KOGURE, N.; FRAZBLAU, S. G.; CRUZ, T. E. E. D.; TAKAYAMA, H.; NONATO, M. G.. Bioactive metabolites of Diaporthe sp. P133, an endophytic fungus isolated from Pandanus amaryllifolius. Journal of Natural Medicines, v.65, p.606-609, 2011. DOI: https://doi.org/10.1007/s11418-011-0518-x

CECCON, E.; HUANTE, P.; RINCÓN, E.. Abiotic factors influencing tropical dry forests regeneration. Brazilian Archives of Biology and Technology, v.49, n.2, p.305-312, 2006. DOI: https://doi.org/10.1590/S1516$\underline{89132006000300016}$

CHATTERJEE, S.; GHOSH, R.; MANDAL, N. C.. Production of bioactive compounds with bactericidal and antioxidant potential by endophytic fungus Alternaria alternata AE1 isolated from Azadirachta indica A. Juss.. Plos One, v.14, n.4, p.e0214744, 2019. DOI: https://doi.org/10.1371/journal.pone.0214744

COSTA, A. T.; GRACIA, A.; SPECIAN, V.; PAMPHILE, J. A.. Prospecção biotecnológica para a produção de enzimas microbianas. In: AZEVEDO, J. L.; PAMPHILE, J. A.; QUECINEVERDI, M. C.; LACAVA, P. T.. Biotecnologia Microbiana Ambiental. Maringá: Eduem, 2018. p.173-194. 
COSTA, F. E. C.; MELO, I. S.. Endophytic and rhizospheric bacteria from Opuntia ficus-indica Mill. and their ability to promote plant growth in cowpea, Vigna unguiculata (L.) Walp. African Journal of Microbiology Research, v.6, p.1345-1353, 2012.

EATON, C. J.; COX, M. P.; SCOTT, B.. What triggers grass endophytes to switch from mutualism to pathogenism?. Plant Science, v.180, n.2, p.190-195, 2011. DOI: https://doi.org/10.1016/i.plantsci.2010.10.002

EKE, P.; KUMAR, A.; SAHU, K. P.; WAKAM, L. N.; SHEORAN, N.; ASHAJYOYHI, M.; PATEL, A.; FEKAMF, B.. Endophytic bacteria of desert cactus (Euphorbia trigonas Mill) confer drought tolerance and induce growth promotion in tomato (Solanum lycopersicum L.). Microbiological Research, v.228, p.e126302, 2019. DOI:

https://doi.org/10.1016/j.micres.2019.126302

ETESAMI, H.; ALIKHANI, H. A.; HOSSEINI, H. M.. Indole-3acetic acid (IAA) production trait, a useful screening to select endophytic and rhizosphere competent bacteria for rice growth promoting agents. Methods X, v.2, p.72-78, 2015. DOI: https://doi.org/10.1016/j.mex.2015.02.008

FERNANDES, E. G.; PEREIRA, O. L.; SILVA, C. C.; BENTO, C. B. P.; QUEIROZ, M. V.. Diversity of endophytic fungi in Glycine max. Microbiological Research, v.181, p.84-92, 2015. DOI: https://doi.org/10.1016/i.micres.2015.05.010

FLORES, A. C.; PAMPHILE, J. A.; SARRAGIOTTO, M. H.; CLEMENTE, E.. Production of 3-nitropropionic acid by endophytic fungus Phomopsis longicolla isolated from Trichilia elegans A. JUSS ssp. elegans and evaluation of biological activity. World Journal of Microbiology and Biotechnology, v.29, p.923-932, 2013. DOI: https://doi.org/10.1007/s11274-013-1251-2

FONSECA-GARCÍA, C.; COLEMAN-DERR, D.; GARRIDO, E.; VISEL, A.; TRINGE, S. G.; PARTIDA-MARTÍNEZ, L. P.. The cacti microbiome: interplay between habitat-filtering and hostspecificity. Frontiers in Microbiology, v.7, p.150, 2016. DOI: https://doi.org/10.3389/fmicb.2016.00150

GLICK, B. R.. Bacteria with ACC deaminase can promote plant growth and help to feed the world. Microbiological

Research, v.169, n.1, p.30-39, 2014. DOI:

https://doi.org/10.1016/i.micres.2013.09.009

GOUGH, D.; THOMAS, J.; OLIVER, S.. Clarifying differences between review designsand methods. Systematic Reviews. v.1, p.2-9, 2012. DOI: https://doi.org/10.1186/2046-4053-1$\underline{28}$

JEEWON, R.; LUCKHUN, A. B.; BHOYROO, V.; SADEER, N. B.; MAHOMOODALLY, F. M.; RAMPADARATH, S.; PUCHOOA, D.; SARMA, V.; DURAIRAJAN, S. S. K.; HYDE, K. D..

Pharmaceutical potential of marine fungal endophytes. In: JHA, S.. Endophytes and Secondary Metabolites.

Switzerland: Springer, 2019. p.1-23. DOI:

https://doi.org/10.1007/978-3-319-76900-4 6-1

KAVAMURA, V. N.; SANTOS, S. N.; SILVA, J. L.; PARMA, M. M.; ÁVILA, L. P.; VISCONTINI, A.; ZUCCHI, T. D.; TAKETANI, R. G.; ANDREOTE, F. D.; MELO, I. S.. Screening of Brazilian cacti rhizobacteria for plant growth promotion under drought.
Microbiological Research, v. 168, p.183-191, 2013. DOI: http://dx.doi.org/10.1016/i.micres.2012.12.002

KOGEL, K. H.; FRANKEN, P.; HUCKELHOVEN, R.. Endophyte or parasite- what decides?. Current Opinon in Plant Biology, v.9, n.4, p.358-63, 2006. DOI: https://doi.org/10.1016/j.pbi.2006.05.001

LACAVA, P. T.; MELO, I. T.; PEREIRA, J. O.. Controle Biológico e Simbiótico de insetos-pragas e doenças por microorganismos endofíticos. In: AZEVEDO, J. L.; PAMPHILE, J. A.; QUECINE-VERDI, M. C.; LACAVA, P. T.. Biotecnologia Microbiana Ambiental. Maringá: Eduem, 2018, p.83-104.

LEE, J. M.; TAN, W. S.; TING, A. S. Y.. Revealing the antimicrobial and enzymatic potentials of culturable fungal endophytes from tropical pitcher plants (Nepenthes spp.). Mycosphere, v.5, n.2, p.364-377, 2014.

LEMANCEAU, P.; BLOUIN, M.; MULLER, D.; LOCCOZ, M.. Let the core microbiota be functional. Trends in Plant Science, v.22, n.7, p.583-595, 2017. DOI:

https://doi.org/10.1016/j.tplants.2017.04.008

LI, G.; LOU, H. X.. Strategies to diversify natural products for drug discovery. Medicinal Research Reviews, v.38, n.4, p.1255-1294, 2018. DOI: https://doi.org/10.1002/med.21474

LIMA, J. V. L.; WEBER, O. B.; CORREIA, D.; SOARES, M. A.; SENABIO, J. Q.. Endophytic bacteria in cacti native to a Brazilian semi-arid region. Plant Soil, v.389, p.25-33, 2015. DOI: https://doi.org/10.1007/s11104-014-2344-X

LIU, C.; LU, J.; LU, L.; LIU, Y.; WANG, F.; XIAO, M.. Isolation, structural characterization and immunological activity of an exopolysaccharide produced by Bacillus licheniformis 8-37-01. Bioresource Technology, v.101, n.14, p.5528-5533, 2010. DOI: https://doi.org/10.1016/j.biortech.2010.01.151

LIU, J.; WANG, X.; PU, H.; LIU, S.; KAN, J.; JIN, C.. Recent advances in endophytic exopolysaccharides: Production, structural characterization, physiological role and biological activity. Carbohydrate Polymers, v.157, p.1113-1124, 2017. DOI: https://doi.org/10.1016/j.carbpol.2016.10.084

LOPEZ, B. R.; BASHAN, Y.; BACILIO, M.. Endophytic bacteria of Mammillaria fraileana, an endemic rock-colonizing cactus of the southern Sonoran Desert. Archives of Microbiology, v.193, p.527-541, 2011. DOI:

https://doi.org/10.1007/s00203-011-0695-8

LYRA, C. P.; SANTOS, D. C.; MONDRAGON-JACOBO, C.; SILVA, M. R. L. B.; MERGULHÃO, A. C. E. S.; MARTÍNEZ-ROMERO, E.. Isolation and molecular characterization of endophytic bacteria associated with the culture of forage cactus (Opuntia spp.). Journal Applied Biomater Biomechical, v.1, p.11-16, 2013.

MAGNANI, M.; FERNANDES, T.; PRETE, C. E. C.; HOMECHIM, M.; ONO, E. Y. S.; VILAS-BOAS, L. A.; SARTORI, D.; FURLANETO, M. C.; FUNGARO, M. H. P.. Molecular identification of Aspergillus spp. isolated from coffee beans. Scientia Agricola, v.62, n.1 p.45-49, 2005. DOI: https://doi.org/10.1590/S0103-90162005000100009

MANJUNATHA, B. S.; SANGEETA, P.; AGGARWAL, C.; 
BANDEPPA, S.; GOVINDASAMY, V.; DUKARE, A. S.; MAHESHWAR S. R.; SATYAVATHI, C. T.; ANNAPURNA, K.. Diversity and tissue preference of osmotolerant bacterial endophytes associated with pearl millet genotypes having differential drought susceptibilities. Microbial Ecology, v.77, p.676-688, 2019. DOI: https://doi.org/10.1007/s00248-018$\underline{1257-2}$

MEIADO, M. V.; MACHADO, M. C.; ZAPPI, D. C.; TAYLOR, N. P.; SIQUEIRA FILHO, J. A.. Ecological attributes, geographic distribution and endemism of cacti from the São Francisco watershed. Gaia Scientia, v.9, n.2, p.40-53, 2015.

MISHRA, A.; JHA, B.. Microbial exopolysacchrides. In: ROSENBERG, E.; DELONG, E. F.; LORY, S.; STACKEDRANDT, E.; THOMPSON, F.. The prokaryotes: applied bacteriology and biotechnology. 4 ed. Heidelberg: Springer, 2013. p.179-192.

MOHER, D.; SHAMSEER, L.; CLARKE, M.; GHERSI, D.; LIBERATI, A.; PETTICREW, M.; SHEKELLE, P.; STEWART, L. A.. Preferred reporting items for systematic review and metaanalysis protocols (PRISMA-P) 2015 statement. Systematic Reviews, v.4, p.2-9, 2015. DOI: https://doi.org/10.1186/2046-4053-4-1

MURPHY, P. G.; LUGO, A. E.. Ecology of tropical dry forest. Annual Review of Ecology, Evolution and Systematics, v.17, p.67-88, 1986.

NAMWONGSA, J.; JOGLOY, S.; VORASOOT, N.; BOONLUE, S.; RIDDECH, N.; MONGKOLTHANARUK, W.. Endophytic bacteria improve root traits, biomass and yield of Helianthus tuberosus L. under normal and deficit water conditions. Journal of Microbiology and Biotechnology, v.29, n.11, p.1777-1789, 2019. DOI: https://doi.org/10.4014/jmb.1903.03062

OLDFIELD, S.. Cactus and succulent plants: status survey and conservation action plant. Gland: International Union for Conservation of Nature and Natural Resources - IUCN, 1997.

ORLANDELLI, R. C.; ALBERTO, R. N.; RUBIN FILHO, C. J.; PAMPHILE, J. A.. Diversity of endophytic fungal community associated with Piper hispidum (Piperaceae) leaves. Genetics and Molecular Research, v.11, n.2, p.1575-1585, 2012. DOI: http://dx.doi.org/10.4238/2012.May.22.7

ORLANDELLI, R. C.; ALMEIDA, T. T.; ALBERTO, R. N.; POLONIO, J. C.; AZEVEDO, J. L.; PAMPHILE, J. A.. Antifungal and proteolytic activities of endophytic fungi isolated from Piper hispidum Sw. Brazilian Journal of Microbiology, v.46, n.2, p.359-366, 2015. DOI: https://doi.org/10.1590/S1517$\underline{838246220131042}$

ORTEGA-BAES, P.; SÜHRING, S.; SAJAMA, J.; SOTOLA, E.; ALONSO-PEDANO, M.; BRAVO, S.; GODÍNEZ-ALVAREZ, H. Diversity and conservation in the cactus family. In: RAMAWAT, T.. Desert plants. Heidelberg: Springer, 2010. p.157-173. DOI: https://doi.org/10.1007/978-3-642-0255018

PÁDUA, A. P. S. P.; FREIRE, K. T. L. S.; OLIVEIRA, T. G. L.; SILVA, L. F.; ARAÚJO-MAGALHÃES, G. R.; AGAMEZMONTALVO, G. S.; SILVA, I. R.; BEZERRA, J. D. P.; SOUZAMOTTA, C. M.. Fungal endophyte diversity in the leaves of the medicinal plant Myracrodruon urundeuva in a Brazilian dry tropical forest and their capacity to produce L- asparaginase. Acta Botanica Brasilica, v.33, n.1, p.39-49,

2019. DOI: https://doi.org/10.1590/0102-

33062018abb0108

PAMPHILE, J. A.; AZEVEDO, J. L.. Molecular characterization of endophytic strains of Fusarium verticillioides (= Fusarium moniliforme) from maize (Zea mays. L). World Journal of Microbiology \& Biotechnology, v.18, p.391-396, 2002. DOI: https://doi.org/10.1023/A:1015507008786

PAMPHILE, J. A.; ROCHA, C. L. M. S. C.; AZEVEDO, J. L.. Cotransformation of a tropical maize endophytic isolate of Fusarium verticillioides (synonym $\mathrm{F}$. moniliforme) with gusA and nia genes. Genetics and Molecular Biology, v.27, n.2, p.253-258, 2004. DOI: https://doi.org/10.1590/S1415$\underline{47572004000200021}$

PIZA, A. C. M. T.; HOKKA, C. O.; SOUSA, C. P.. Endophytic actinomycetes from Miconia albicans (Sw.) Triana (Melastomataceae) and evaluation of its antimicrobial activity. Journal of Scientific Research and Reports, v.4, n.4, p.281-291, 2015. DOI:

https://doi.org/10.9734/JSRR/2015/13237

PUENTE, M. E.; LI, C. Y.; BASHAN, Y.. Rock-degrading endophytic bacteria in cacti. Environmental and Experimental Botany, v.66, n.3, p.389-401, 2009. DOI: https://doi.org/10.1016/i.envexpbot.2009.04.010

REZENDE, C. L.; SCARANO, F. R.; ASSAD, E. D.; JOLY, C. A.; METZGER, J. P.; STRASSBURG, B. B. N.; TABARELI, M.; MITTERMEIER, R. A.. From hotspot to hopespot: An opportunity for the Brazilian Atlantic Forest. Perspectives in Ecology and Conservation, v.16, n.4, p.208-214, 2018. DOI: https://doi.org/10.1016/j.pecon.2018.10.002

ROBINSON, R. J.; FRAAIJE, B. A.; CLARK, I. M.; JACKSON, R. W.; HIRSCH, P. R.; MAUCHLINE, T. H.. Endophytic bacterial community composition in wheat (Triticum aestivum) is determined by plant tissue type, developmental stage and soil nutrient availability. Plant Soil, v.405, p.381-396, 2016. DOI: https://doi.org/10.1007/s11104-015-2495-4

ROCHA, P. A.; RUIZ-ESPARZA, J.; RIBEIRO, A. S.; FERRARI, S. F.. Species diversity and seasonal variation in the composition of a bat community in the semi-arid Brazilian Caatinga. Acta Scientiarum Biological Sciences, v. 37, n.2, p.197-203, 2015. DOI:

https://doi.org/10.4025/actascibiolsci.v37i2.25746

ROJAS-ARÉCHIGA, M.; VÁZQUEZ-YANES, C.. Cactus seed germination: a review. Journal of Arid Environments, v.44, n.1 p.85-104, 2000. DOI:

https://doi.org/10.1006/jare.1999.0582

SAMPAIO, R. F.; MANCINI, M. C.. Estudos de revisão sistemática: um guia para síntese criteriosa da evidência científica. Revista Brasileira de Fisioterapia, v.11, n.1, p.8389, 2007.

SÁNCHEZ-AZOFEIFA, G. A.; QUESADA, M.; RODRIGUEZ, J. P.; NASSAR, J. M.; STONER, K. E.; CASTILLO, A.; GARVIN, T.; ZENT, E. L.; CALVO-ALVARADO, J. C.; KALACSKA, M. E. R.; FAJARDO, L.; GAMON, J. A.; CUEVAS-REYES, P.. Research priorities for neotropical dry forests. Biotropica, v.37, n.4, p.477-485, 2005. 
SANTOS-DÍAZ, M. S.; CAMARENA-RANGEL, N. G.. Cacti for production of metabolites: current state and perspectives. Applied Microbiology and Biotechnology, v.103, p.86578667, 2019. DOI: https://doi.org/10.1007/s00253-01910125-5

SERRANO, N. F. G.; RODRIGUES, L. R. M.; HOKKA, C. O.; SOUSA, C. P.; TEIXEIRA, J. A. C.; MUSSATO, S. I. D.. Optimal glucose and inoculum concentrations for production of bioactive molecules by Paenibacillus polymyxa RNC-D. Chemical Papers, v.66, p.1111-1117, 2012. DOI: https://doi.org/10.2478/s11696-012-0242-3

SHOKRI, D.; EMTIAZI, G.. Indole-3-Acetic Acid (IAA) Production in Symbiotic and Non-Symbiotic Nitrogen-Fixing Bacteria and its Optimization by Taguchi Design. Current Microbiology, v.61, p.217-225, 2010. DOI: https://doi.org/10.1007/s00284-010-9600-v

SILVA, M. L. R. B.; FIGUEIRÔA, C. S.; MERGULHÃO, A. C. E. S.; LYRA, M. C. C. P.. Identification of diazotrophs isolated from palm cultivars (Opuntia and Nopalea) using the reca gene. Bioscience Journal, v.3, p.577-583, 2015.

SINGH, B. K.; LIU, H.; TRIVEDI, P.. Eco-holobiont: A new concept to identify drivers of host-associated microorganisms. Environmental Microbiology, v.22, n.2, p.564-567, 2020. DOI: https://doi.org/10.1111/14622920.14900

SINGH, D. K.; SHARMA, V. K.; KUMAR, J.; MISHRA, A.; VERMA, S. K.; SIEBER, T. N.; KHARWAR, R. N.. Diversity of endophytic mycobiota of tropical tree Tectona grandis Linn.f.: Spatiotemporal and tissue type effects. Scientific Reports, v.7, p.e3745, 2017. DOI: https://doi.org/10.1038/s41598-017-03933-0

SOBRAL, J. K.; MARCON, J.; LIMA, A. O. S.; LACAVA, P. T.. Aspectos gerais de micro-organismos endofíticos. In: ARAÚJO, W. L.; QUECINE, C.; LACAVA, P. T.; AGUILARVILDOSO, C. I.; MARCON, J.; LIMA, A. O.; SOBRAL, J. K.; PIZZIRANI-KLEINER, A. A.; AZEVEDO, J. L.. Micro-organismos endofíticos: aspectos teóricos e práticos de isolamento e caracterização. Santarém: UFOPA, 2014. p.257-312.

SPECIAN, V.; SARRAGIOTTO, M. H.; PAMPHILE, J. A.; CLEMETE, E.. Chemical characterization of bioactive compounds from the endophytic fungus Diaporthe helianthi isolated from Luehea divaricata. Brazilian Journal of Microbiology, v.43, n.3, p.1174-1182, 2012. DOI: https://doi.org/10.1590/S1517-83822012000300045

STRASSBURG, B. B. N.; BROOKS, T.; FELTRAN-BARBIERI, R.; IRIBARREM, A.; CROUZEILLES, R.; LOYOLA, R.; LATAWIEC, A. E.; OLIVEIRA FILHO, F. J. B.; SCARAMUZZA, C. A. M.; SCARANO, F. R.; SOARES FILHO, B.; BALMFORD, A.. Moment of truth for the Cerrado hotspot. Nature Ecology \& Evolution, v.1, p.e0099, 2017. DOI: https://doi.org/10.1038/s41559-017-0099
TERRAZAS, T.; MAUSETH, J. D.. Shoot anatomy and morphology. In: NOBEL, P. S.. The cacti: biology and uses. California: University of California Press, 2002. p.23-40.

THATOI, H.; BEHERA, B. C.; MISHRA, R. R.; DUTTA, S. K.. Biodiversity and biotechnological potential of microorganisms from mangrove ecosystems: a review. Annals of Microbiology, v.63, p.1-19, 2013. DOI: https://doi.org/10.1007/s13213-012-0442-7

UROZ, S.; COURTY, P. E.; OGER, P.. Plant symbionts are engineers of the plant-associated microbiome. Trends in Plant Science, v.24, n.10, p.905-916, 2019. DOI: https://doi.org/10.1016/j.tplants.2019.06.008

UNTERSEHER, M.; SIDDIQUE, A. B.; BRACHMANN, A.; PERŠOH, D.. Diversity and composition of the leaf mycobiome of beech (Fagus sylvatica) are affected by local habitat conditions and leaf biochemistry. Plos One, v.11, n.4, p.e0152878, 2016. DOI: https://doi.org/10.1371/journal.pone.0152878

UNTERSEHER, M.; PETZOLD, A.; SCHNITTLER, M.. Xerotolerant foliar endophytic fungi of Populus euphratica from the Tarim River basin, Central China are conspecific to endophytic ITS phylotypes of Populus tremula from temperate Europe. Fungal Diversity, v.54, p.133-142, 2012. DOI: https://doi.org/10.1007/s13225-012-0167-8

VELOSO, H. P.; RANGEL FILHO, A. L.; LIMA, J. C. A.. Classificação da vegetação brasileira, adaptada a um sistema universal. Rio de Janeiro: IBGE, 1991.

WALLACE, R. S.; GIBSON, A. C.. Evolution and systematics. In: PARK, S.. Cacti: biology and uses. Califórnia: University of California Press, 2002. p.280-351.

YOUSEF, R. H.; BAOTHMAN, O. A. S.; ABDULAAL, W. H.; ABOGOLAYEL, M. K.; DARWISH, A. A.; MOSELHY, S. S.; AHMED, Y. M.; HAKEEM, K. R.. Potential antitumor activity of exopolysaccharide produced from date seed powder as a carbon source for Bacillus subtilis. Journal of Microbiological Methods, v.170, p.e105853, 2020. DOI: https://doi.org/10.1016/j.mimet.2020.105853

ZAPPI, D. C.; TAYLOR, R. N. P.; MACHADO, M. C.. Cactaceae. In: FORZZA, R. C.; BAUMGRATZ, F. A.; BICUDO, C. E. M.; CANHOS, D. A. L.; CARVALHO JUNIOR, A. A.; COSTA, A.; COSTA, D. P.; HOPKINS, M.; LEITMAN, P. M.; LOHM ANN, L. G.; NIC LU GHADHA, E.; MAIA, L. C.; MARTINELLI, G.; MENEZES, M.; MORIM, M. P.; NADRUZ COELHO, M. A.; PEIXOTO, A. L.; PIRANI, J. R.; PRADO, J.; QUEIROZ, L. P.; SOUZA, S.; SOUZA, V. C.; STEHMANN, J. R.; SYLVESTRE, L. S.; WALTER, B. M. T.; ZAPPI, D. C.. Catálogo de Plantas e Fungos do Brasil. Rio de Janeiro: Jardim Botânico do Rio de Janeiro, 2010. p.832-896.

ZAPPI, D.; TAYLOR, N.; SANTOS, M. R.; LAROCCA, J.. Cactaceae: Lista de Espécies da Flora do Brasil. Rio de Janeiro: Jardim Botânico do Rio de Janeiro, 2015.

A CBPC - Companhia Brasileira de Produção Científica (CNPJ: 11.221.422/0001-03) detém os direitos materiais desta publicação. Os direitos referem-se à publicação do trabalho em qualquer parte do mundo, incluindo os direitos às renovações, expansões e disseminações da contribuição, bem como outros direitos subsidiários. Todos os trabalhos publicados eletronicamente poderão posteriormente ser publicados em coletâneas impressas sob coordenação da Sustenere Publishing, da Companhia Brasileira de Produção Científica e seus parceiros autorizados. Os (as) autores (as) preservam os direitos autorais, mas não têm permissão para a publicação da contribuição em outro meio, impresso ou digital, em português ou em tradução. 